\title{
DESIGN AND DEVELOPMENT OF LOSARTAN POTASSIUM FLOATING DRUG DELIVERY SYSTEMS
}

\section{PRASANTA KUMAR MOHAPATRA ${ }^{\mathrm{a}^{*}}$, CH. PRATHIBHA ${ }^{\mathrm{b}}$, VIVEK TOMER ${ }^{\mathrm{a}}$, MANDEEP KUMAR GUPTA ${ }^{\mathrm{a}}$, SATYAJIT SAHOOc}

aMoradabad Educational Trust Group of Institutions Faculty of Pharmacy, Moradabad, Utter Pradesh, India, bLydia College of Pharmacy, East Godavari District, Andhra Pradesh, India, cC. U. Shah College of Pharmacy and Research, Surendranagar, Gujrat, India

Email: mahapatra.kjr@gmail.com

Received: 27 Jul 2018, Revised and Accepted: 12 Sep 2018

ABSTRACT

Objective: The current study was projected to prepare a losartan potassium gastroretentive drug delivery system (GRDDS) of floating tablets was planned to enhance the gastric residence time, thus prolong the drug release.

Methods: Effervescent floating matrix tablets of losartan potassium were prepared by direct compression technique using polymers like HPMC $\mathrm{k} 4 \mathrm{~m}$, guar gum, and gum karaya, with lubricants magnesium stearate and talc. In the present study, sodium bicarbonate was incorporated as a gas generating agent. Total nine formulations were designed and evaluated for pre-compression parameters known as the angle of repose, bulk density, tapped density, Hausner's ratio, compressibility index, and post-compression parameters are uniformity of weight, hardness, and drug content percentage, variability, in vitro buoyancy, dissolution studies, and Fourier transform infrared spectroscopy (FTIR).

Results: An in vitro dissolution study was carried out by using buffer $\mathrm{pH} 1.2$. From in vitro dissolution studies, it has been found that an increase in polymer concentration diminishes the drug release profile. The in vitro drug release percentage from F4-F9 formulations ranged from 60.28\%$98.66 \%$ at the closing of $12 \mathrm{~h}$ and buoyancy found over $12 \mathrm{~h}$.

Conclusion: The in vitro drug release from F1-F3 and F7-F9 followed zero-order, F4 followed Higuchi order, F5 and F6 followed Hixon-Crowell release kinetics. The drug release mechanism was set up to be F1-F8 non-Fickian (anomalous behavior) and F9 having Fickian diffusion type.

Keywords: Losartan potassium, Hpmc k4m, Guar gum, and Gum karaya, Direct compression technique, Floating drug delivery systems (FDDS)

(C) 2018 The Authors. Published by Innovare Academic Sciences Pvt Ltd. This is an open access article under the CC BY license (http://creativecommons.org/licenses/by/4.0/) DOI: http://dx.doi.org/10.22159/ijap.2018v10i6.28782

\section{INTRODUCTION}

The oral route is the most convenient and extensively used route for drug administration in the body. It is likely that at least $90 \%$ of all the drugs administered by the oral route [1]. The oral route is the most preferred route, and it received more interest in the pharmacy sector because it provides more flexibility in designing of the dosage form as compared to another path. There are different drug deliveries to administer the drug by the oral route. The two difficulties of drug delivery systems (DDS) are, less gastric retention time and less gastric emptying (GE) time. Decrease response of dose due to, incomplete drug release from the dosage form in the absorption zone $[2,3]$. Due to physiological property the drug, absorption is unsatisfactory and highly fluctuating among and between individuals and generally affected by the gastrointestinal transit of the form, specifically its residence time in gastric, which seems to be one of the important causes of the overall transit time variability [4]. In the delivery of drugs with narrow absorption windows in the small intestinal region, the gastric retention will provide advantages [4]. Various approaches have been hypothesized to control the residence of DDS in the upper part of the gastrointestinal tract (GIT) such as the incorporation of passage delaying food agents, ion exchange resins, raft system, high-density DDS, floating drug delivery systems (FDDS), swelling or expandable DDS and mucoadhesive DDS [5, 6, 22]. The oral controlled DDS main objective is to attain more expected and enhanced bioavailability [7]. The common property of conventional controlled release (CR) technologies is that a large part of the drug load is released in the colon, where the dosage form stays for a relatively long period. This delivery approach, while desirable for many molecules, was found to be inappropriate for drugs that are poorly absorbed from the lower portion of the GIT. Under certain circumstances extending the gastric retention of a DDS is necessary for achieving the bigger therapeutic advantage of the drug. The benefit of gastric retention is for those drugs that are absorbed in the proximal portion of the GIT, and the drugs that are having a solubility less or a dip in the alkaline
$\mathrm{pH}$ may advantage of gastric retention [8]. Drug delivery to the proximal small intestine and local and sustained drug delivery to the abdominal to treat certain diseases, extending gastric retention of the therapeutic substance may offer several benefits including enhancement of therapeutic efficacy and possible reduction of the dose size, improved bioavailability [9]. Fundus and body is a component part of the proximal stomach, which functions as a reservoir for swallowing materials, whereas the major site of mixing motions is the distal region (pylorus), conveying as a pump to push gastric contents for GE $[10,22]$. In, fasting as well as fed states the GE occurs. As a consequence of gastric contractions, the GE occurs and nature depends upon the contents of the stomach. The appropriate classification of GE can be digestible solids, indigestible solids and GE of liquid. Due to the generation of intragastric pressure because of the gentle muscular contractions happening mainly from the proximal stomach, i.e. from the upper body of the stomach the liquids can be removed [11]. Compare to all the DDS the FDDS have a bulk density is lesser than gastric fluids and so linger buoyant in the stomach without disturbing GE rate for an extended period of time [22].

\section{MATERIALS AND METHODS}

\section{Materials}

Losartan potassium was procured from Farma glow Ltd, Mumbai, India and guar gum were procured from Oxford Chemicals, Delhi. Gum karaya and HPMC k15m are obtained from NR chemicals limited, Mumbai. Talc and magnesium stearate were procured from SD Fine Chem. Ltd, Mumbai, India, and sodium bicarbonate were obtained from Rankem Ltd., Delhi. The residual reagents which were used having an analytical grade $[16,17]$.

\section{Methods}

Preparation of losartan potassium floating tablets

All the required ingredients sufficient for 20 tablets were weighed accurately and thoroughly mixed after passing through the sieve no. 
22 in order to attain uniformity. Initially, required an amount of the active ingredient, i.e., losartan potassium and the polymer (guar gum/gum karaya/HPMC k4m/a combination of these polymers) were calculated accurately and were mixed thoroughly with each other. Later on, an accurate amount of the effervescent agent $\mathrm{NaHCO}_{3}$ was added to the powder and mixed individually. Then the diluent, i.e., mannitol was mixed uniformly with the blend. Magnesium stearate and talc were then mixed with the tablet mixture as a lubricant. Tablets containing losartan potassium equivalent to $138.5 \mathrm{mg}$ were compressed by using the 10.0millimeter diameter, spherical tablet punches on a 16 station rotary compression machine at the hardness of 5 to $6 \mathrm{~kg} / \mathrm{cm}^{2}$. The composition of all formulations was given in table $1[14,19]$.

\section{Evaluation parameters}

\section{Pre-compression parameters of losartan potassium granules}

\section{Angle of repose}

The angle of repose has been set at the maximum angle possible between the surfaces of a pile of powder and horizontal plane. Here the fixed funnel method was employed. A funnel was set with its crest at a given height (h), above a level horizontal surface on which a graph paper was placed. The powder was watchfully poured through a funnel till the apex of the conical pile just touches the top of the funnel. By using the below-given formula, the angle of repose was calculated $[14,18]$.

$$
\theta=\tan ^{-1}\left(\frac{\mathrm{h}}{\mathrm{r}}\right)
$$

Where,

$\theta=$ angle of repose,

$\mathrm{h}=$ height of pile,

$\mathrm{r}=$ radius of the pile.

\section{Bulk density}

It is the ratio of the mass of the powder taken with its bulk volume. The shape and cohesiveness of particles, particle size distribution, was depended on bulk density. A fixed quantity of powder was cautiously poured into the graduated measuring cylinder through an appropriate size funnel and volume was calculated, and it is called as bulk volume. Bulk density is expressed in $\mathrm{kg} / \mathrm{m}^{3}$ and is given by $[15,18]$.

$$
\rho_{\mathrm{b}}=\mathrm{M} / \mathrm{V}_{\mathrm{a}}
$$

Where,

$\rho_{\mathrm{b}}=$ bulk density $\left(\mathrm{kg} / \mathrm{m}^{3}\right)$,

$\mathrm{M}=$ mass of powder $(\mathrm{kg})$,

$\mathrm{V}_{\mathrm{o}}=$ bulk volume of powder $\left(\mathrm{m}^{3}\right)$.

\section{Tapped density}

In a clean, dry $100 \mathrm{ml}$ measuring cylinder $10 \mathrm{~g}$ of powder was loaded. The loaded cylinder was then tapped 100 times by tapped density apparatus or manually by hand from a fixed height and then tapped volume, tapped density was measured.

Which is specified in $\mathrm{kg} / \mathrm{m}^{3}$ and calculated by following formula $[14,18]$.

$$
\rho_{\mathrm{t}}=\mathrm{M} / \mathrm{V}_{\mathrm{t}}
$$

Where,

$\rho_{\mathrm{t}}=$ tapped density $\left(\mathrm{kg} / \mathrm{m}^{3}\right)$,

$\mathrm{M}=$ mass of powder $(\mathrm{kg})$,

$\mathrm{V}_{\mathrm{t}}=$ tapped volume of powder $\left(\mathrm{m}^{3}\right)$.

\section{Compressibility index}

From the values of bulk and tapped densities a secondary method for determining powder flow is Carr's index. The powder arch potency or bridge strength and stability of the powder were directly measured by the percentage compressibility. Each formulation's Carr's index was calculated by the below-given equation $[15,18]$.

$$
\text { Carr's index }=\left(\rho_{\mathrm{t}}-\rho_{\mathrm{b}} / \rho_{\mathrm{t}}\right) \mathrm{x} 100
$$

Where,

$$
\begin{aligned}
& \rho_{\mathrm{t}}=\text { tapped density }\left(\mathrm{kg} / \mathrm{m}^{3}\right), \\
& \rho_{\mathrm{b}}=\text { bulk density }\left(\mathrm{kg} / \mathrm{m}^{3}\right)
\end{aligned}
$$

\section{Hausner's ratio}

Hausner's ratio is calculated by tapped density versus bulk density [18].

$$
\text { Hausner's ratio }=(\text { Tapped Density) } / \text { (Bulk Density) }
$$

\section{Post-compression parameters}

\section{Tablet thickness and diameter}

Thickness, as well as the diameter of the tablets, was determined by using a vernier caliper. By picking three tablets from each formulation individually and randomly the tablet's thickness was measured $[14,16,17]$.

\section{Hardness}

The hardness test is used to check the binding strength of a tablet. Due to tablets, insufficient hardness may undergo chipping or breakage during transportation or breakage during handling. Randomly five tablets were selected and with the help of Monsanto hardness tester hardness of each tablet was calculated. The tablet hardness is commonly measured in $\mathrm{kg} / \mathrm{cm}^{2}[16,21]$.

\section{Friability}

By taking randomly 20 tablets into Roche friabilator, the friability of tablets was determined. It is expressed in percentage. Primarily 20 tablets were weighed and transferred into Roche friabilator. At, $25 \mathrm{rpm}$ for $4 \mathrm{~min}$ the friabilator drum was rotated, or the drum was rotated total 100 revolutions. After completion of 100 revolutions, the 20 tablets were removed and again weighted. The weight loss percentage was then measured by the below-given equation $[15,16,17]$.

$$
\mathrm{f}=\left(\mathrm{W}_{0}-\frac{\mathrm{W}}{\mathrm{W}_{0}}\right) \times 100
$$

Where,

$\mathrm{f}=$ friability,

$\mathrm{W}_{0}=$ initial weight,

$\mathrm{W}=$ final weight.

\section{Uniformity of weight}

The weight variation arises due to the non-uniform size of granules, poor flow property, and mechanical problems. If the granular size is large, non-uniformly the dies will be filled. And due to the formation of non-uniform size tablets, the drug content also became nonuniform.

Method: Uncoated tablets comply with this test.

The 20 tablets average weight is determined and compared with individual weight. From the average weight, not more than two tablets deviate from a percentage larger than that given. If more than two tablet weight is outside the \pm average percentage weight then (according to IP) the test will be failed $[14,15,17]$.

\section{Uniformity of drug content}

In the formulation, the drug content was checked the dose uniformity. Randomly 10 tablets were selected individually and powered. The randomly selected powdered individual tablets were placed in a $100 \mathrm{ml}$ volumetric flask containing $\mathrm{pH} 1.2$ buffer solution and left undisturbed overnight. The drug content was determined after suitable dilutions by U. V-spectrophotometer at $234 \mathrm{~nm}$ against blank $[14,19,21]$. 


\section{Buoyancy studies}

To evaluate the floating lag time and extent of floating the in vitro buoyancy was conducted. The glass beaker containing $0.1 \mathrm{~N} \mathrm{HCl} 250$ $\mathrm{ml}$ buffer $\mathrm{pH} 1.2$ into it, the tablets were placed. Then the floating lag time (tablet to reach from the water inside to surface) and entire floating time (tablet's floating duration) were measured [14, 19, 20].

\section{Drug excipients compatibility studies}

In all pharmaceutical dosage forms, the excipients are found almost as integral components. The careful selection of the excipients is the successful formulation of a stable and effective solid dosage form. The role of excipients to simplify administration, promote the bioavailability and the constant release of the drug and also protect it from deterioration. One of the strongest analytical techniques to detect functional groups of a drug is infrared spectroscopy. Fourier transform infrared spectroscopy (FTIR) studies the interaction between a pure drug and its formulations were evaluated. In the current study, the employed method was a potassium bromide pellet method. The dry powdered potassium bromide was thoroughly mixed with the sample. The mixture was then compacted by using dies to form a disc. In the spectrophotometer, the spectrum was recorded after placing the disc $[16,17,20]$.

\section{In vitro dissolution studies using pH 1.2 buffer}

In, USP Type II apparatus (paddle type) the release rate of losartan potassium floating tablets was determined. By using $900 \mathrm{ml}$ of $0.1 \mathrm{~N} \mathrm{HCl},(\mathrm{pH} 1.2)$ at $37 \pm 0.5{ }^{\circ} \mathrm{C}$ at $50 \mathrm{rpm}$ for $12 \mathrm{~h}$ the dissolution test was conducted. From the dissolution apparatus, the $5 \mathrm{ml}$ sample was withdrawn at a specified time intervals, and every time $5 \mathrm{ml}$ of fresh dissolution medium was replaced. Through a $0.45 \mu \mathrm{m}$ membrane filter, the collected samples were filtered and if necessary diluted. These sample solutions' absorbance was measured at $234 \mathrm{~nm}$ by using a U. V-Visible spectrophotometer $[14,19,21]$.

\section{Drug release kinetics}

To inspect the drug release mechanism and kinetics, the cumulative percentage of drug release data were fitted to models presenting zeroorder (cumulative percentage of drug release versus time), first-order (log cumulative percentage of drug remaining versus time), Higuchi (cumulative percentage drug release versus square root of time), HixonCrowell (cube root of drug percentage remaining versus time in ' $h$ ') and Korsmeyer-Peppas (log cumulative percentage drug release versus log time) correspondingly $[14,17,20]$.

\section{RESULTS AND DISCUSSION}

Pre-compression parameters of losartan potassium granules

The losartan potassium formulations F1 to F9 the Carr's index and Hausner's ratio data between 11.51 (F7) to 15.13 (F1) and 1.13 (F7) to 1.18 (F8). The losartan potassium prepared tablets bulk density and tapped density was found in between 0.326 (F6) to 0.392 (F7) and 0.377 (F4) to 0.443 (F7) respectively. The angle of repose values range is in between 20.14 (F1) to 29. 2 (F6) indicate good flow property about the granules.

\section{Post-compression parameters}

In the formulations, the drug content values vary from $98.25 \%$ (F2) to $99.49 \%$ (F5). The hardness and friability of the prepared gastro retentive drug delivery system (GRDDS) of losartan potassium were found in between the range of 5.02 (F1) to 5.94 (F2) $\mathrm{kg} / \mathrm{cm}^{2}$ and $0.14 \%$ (F9) to $0.52 \%$ (F6). The thickness and weight variation data of the GRDDS of losartan potassium tablets were found in between $3.93 \mathrm{~mm}$ (F4) to $4.24 \mathrm{~mm}$ (F5) and $296.45 \mathrm{mg}$ (F5) to $301.12 \mathrm{mg}$ (F4), were presented in table 3.

Table 1: Formulation composition of losartan potassium

\begin{tabular}{|c|c|c|c|c|c|c|c|c|c|}
\hline Ingredients & F1 & F2 & F3 & F4 & F5 & F6 & F7 & F8 & F9 \\
\hline Losartan potassium $(\% \mathrm{w} / \mathrm{w})$ & 138.5 & 138.5 & 138.5 & 138.5 & 138.5 & 138.5 & 138.5 & 138.5 & 138.5 \\
\hline HPMC K4M (\%w/w) & 69.25 & - & - & 103.875 & - & - & 34.625 & 34.625 & - \\
\hline Guar gum $(\% \mathrm{w} / \mathrm{w})$ & - & 69.25 & - & - & 103.875 & - & - & 34.625 & 34.625 \\
\hline Gum karaya $(\% \mathrm{w} / \mathrm{w})$ & - & - & 69.25 & - & - & 103.875 & 34.625 & - & 34.625 \\
\hline Mannitol (\%w/w) & 30.25 & 30.25 & 30.25 & 45.625 & 45.625 & 45.625 & 30.25 & 30.25 & 30.25 \\
\hline Sodium bicarbonate $(\% \mathrm{w} / \mathrm{w})$ & 50 & 50 & 50 & 50 & 50 & 50 & 50 & 50 & 50 \\
\hline Talc $(\% w / w)$ & 6 & 6 & 6 & 6 & 6 & 6 & 6 & 6 & 6 \\
\hline Magnesium Stearate $(\% w / w)$ & 6 & 6 & 6 & 6 & 6 & 6 & 6 & 6 & 6 \\
\hline Total Weight (mg) & 300 & 300 & 300 & 350 & 350 & 350 & 300 & 300 & 300 \\
\hline
\end{tabular}

HPMC-Hydroxy propyl methyl cellulose

Table 2: Pre-compression parameters

\begin{tabular}{|c|c|c|c|c|c|}
\hline Formulation & $\begin{array}{l}\text { Bulk density } \\
\left(\mathrm{kg} / \mathrm{m}^{3}\right)^{*}\end{array}$ & Tapped density $\left(\mathrm{kg} / \mathrm{m}^{3}\right)^{*}$ & Carr's index (\%)* & Hausner's ratio* & Angle of repose $\left({ }^{\circ}\right)^{*}$ \\
\hline F1 & $0.359 \pm 0.56$ & $0.423 \pm 0.05$ & $15.13 \pm 0.17$ & $1.17 \pm 0.03$ & $20.14 \pm 0.41$ \\
\hline $\mathrm{F} 2$ & $0.375 \pm 0.25$ & $0.441 \pm 0.12$ & $14.97 \pm 0.14$ & $1.17 \pm 0.01$ & $25.11 \pm 1.27$ \\
\hline F3 & $0.355 \pm 0.15$ & $0.412 \pm 0.31$ & $13.83 \pm 0.19$ & $1.16 \pm 0.03$ & $20.14 \pm 3.01$ \\
\hline $\mathrm{F} 4$ & $0.326 \pm 0.17$ & $0.377 \pm 0.15$ & $13.53 \pm 0.24$ & $1.15 \pm 0.01$ & $29.2 \pm 0.94$ \\
\hline F5 & $0.361 \pm 0.18$ & $0.423 \pm 0.18$ & $14.66 \pm 0.16$ & $1.16 \pm 0.03$ & $28.5 \pm 1.44$ \\
\hline F6 & $0.326 \pm 0.16$ & $0.377 \pm 0.19$ & $13.53 \pm 0.18$ & $1.15 \pm 0.01$ & $29.2 \pm 0.41$ \\
\hline F7 & $0.392 \pm 0.17$ & $0.443 \pm 0.17$ & $11.51 \pm 0.24$ & $1.13 \pm 0.04$ & $25.27 \pm 0.59$ \\
\hline F8 & $0.363 \pm 0.21$ & $0.423 \pm 0.05$ & $14.18 \pm 0.21$ & $1.18 \pm 0.03$ & $22.8 \pm 0.93$ \\
\hline F9 & $0.365 \pm 0.16$ & $0.416 \pm 0.06$ & $12.26 \pm 0.04$ & $1.14 \pm 0.02$ & $25.23 \pm 0.32$ \\
\hline
\end{tabular}

*mean \pm standard deviation (SD), $\mathrm{n}=3$

Table 3: Post-compression parameters

\begin{tabular}{|c|c|c|c|c|c|}
\hline Formulation & Thickness (mm)* & Hardness $\left(\mathrm{kg} / \mathrm{cm}^{2}\right)^{*}$ & Friability (\%)* & Uniformity of weight (mg)* & Assay (\%)* \\
\hline F1 & 4.02 & 5.02 & 0.46 & 300.4 & 99.47 \\
\hline $\mathrm{F} 2$ & 3.94 & 5.94 & 0.35 & 297.39 & 98.25 \\
\hline F3 & 4.13 & 5.30 & 0.26 & 298.69 & 98.38 \\
\hline $\mathrm{F} 4$ & 3.93 & 5.42 & 0.45 & 301.12 & 98.53 \\
\hline F5 & 4.24 & 5.24 & 0.31 & 296.45 & 99.49 \\
\hline F6 & 4.06 & 5.06 & 0.52 & 297.26 & 97.27 \\
\hline F7 & 4.06 & 5.21 & 0.23 & 297.59 & 98.68 \\
\hline F8 & 3.95 & 5.38 & 0.15 & 299.35 & 99.24 \\
\hline F9 & 4.16 & 5.12 & 0.14 & 298.95 & 99.39 \\
\hline
\end{tabular}

*mean \pm standard deviation (SD), $\mathrm{n}=3$ 
Table 4: In vitro buoyancy properties of losartan potassium

\begin{tabular}{lll}
\hline Formulation & Floating lag time $(\mathbf{s})^{*}$ & Total floating time (h)* \\
\hline F1 & 63 & $>12$ \\
F2 & 75 & $>12$ \\
F3 & 95 & $>12$ \\
F4 & 70 & $>12$ \\
F5 & 85 & $>12$ \\
F6 & 92 & $>12$ \\
F7 & 87 & $>12$ \\
F8 & 91 & $>12$ \\
F9 & 98 & $>12$ \\
\hline
\end{tabular}

*mean \pm standard deviation (SD), n=3

\section{Floating property}

The all GRDDS of losartan potassium floating lag time values vary in between 63 and $98 \mathrm{~s}$ and total floating time was found more than $12 \mathrm{~h}$.

\section{FTIR studies}

In the current study, Fourier transforms infrared spectroscopy (FTIR) data of the best formulation were matched with the standard spectrum of pure drug losartan potassium over the range 400-4000 $\mathrm{cm}^{-1}$ analyzed. The spectrum of pure losartan potassium shows prominent and strong absorption bands at wave numbers of $1256.53 \mathrm{~cm}^{-1}, 2870.26 \mathrm{~cm}^{-1}, 3172.30 \mathrm{~cm}^{-1}$ and $762.24 \mathrm{~cm}^{-1}$ corresponding to cyclic amines, $\mathrm{C}-\mathrm{H}$ stretches, $\mathrm{O}-\mathrm{H}$ bending and Chlorine, respectively. The FTIR spectrum of the optimized formulation displayed the characteristic bands of both drug and excipient without any significant spectral shift. This suggested there was no potential chemical interaction between the components of the formulations

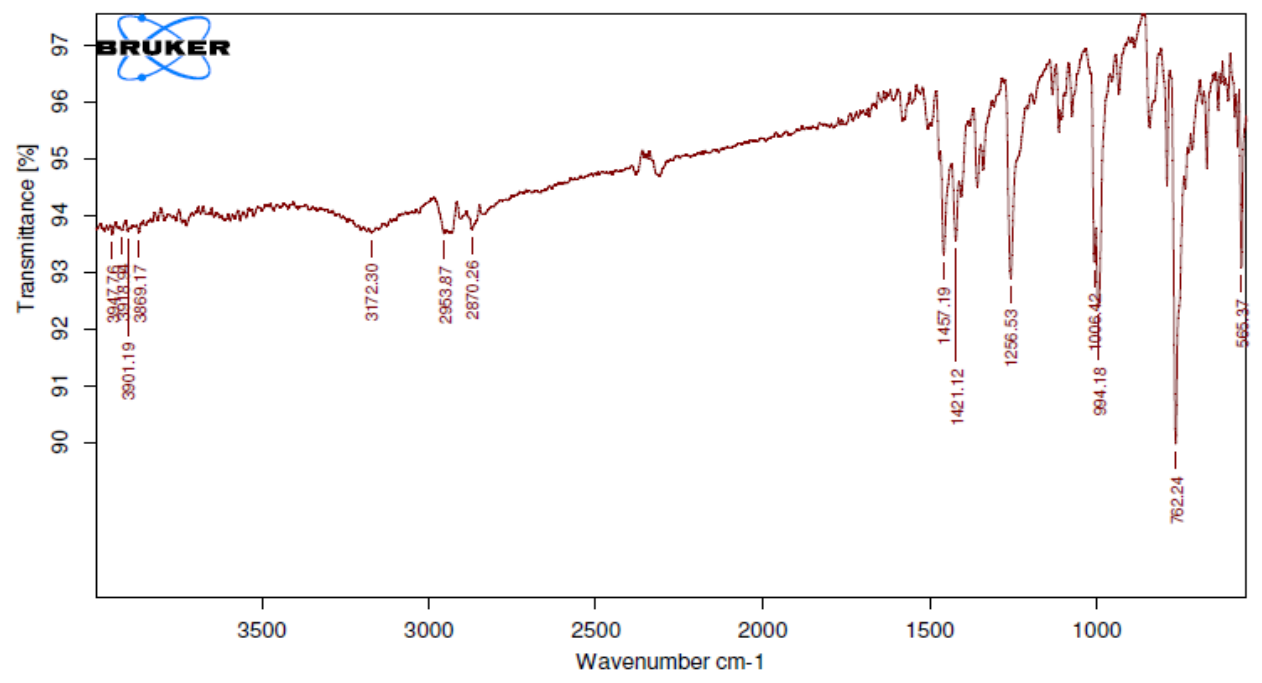

Fig. 1: FTIR spectrum of pure losartan potassium

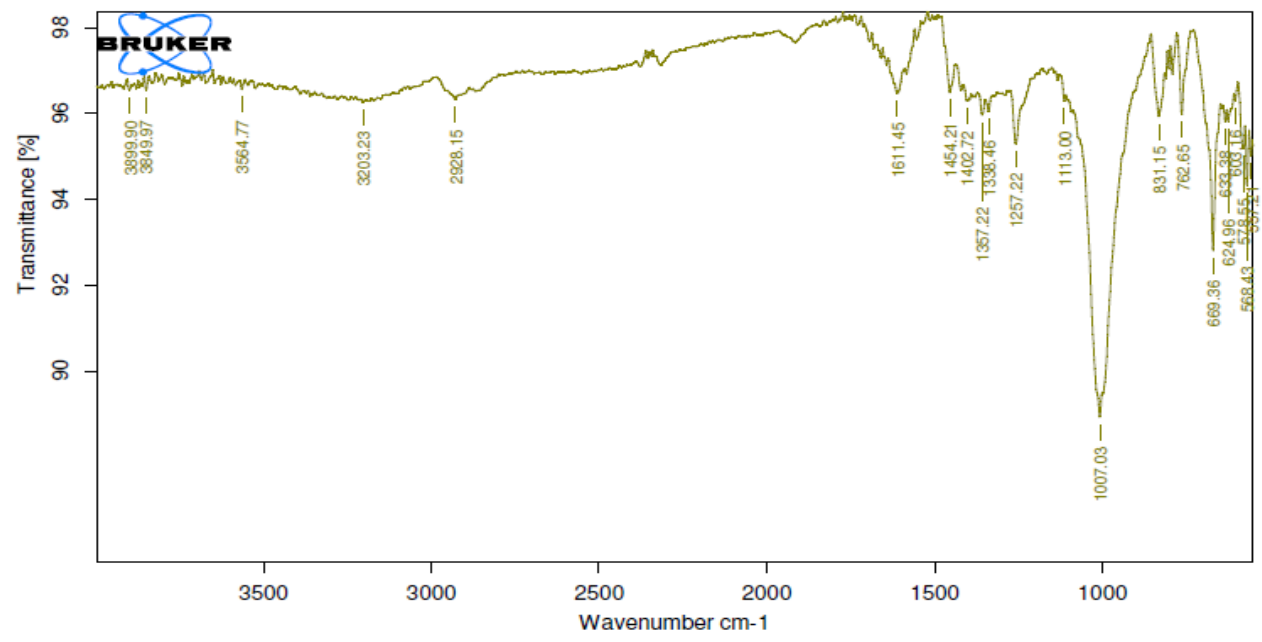

Fig. 2: FTIR spectrum of pure losartan potassium with excipients 


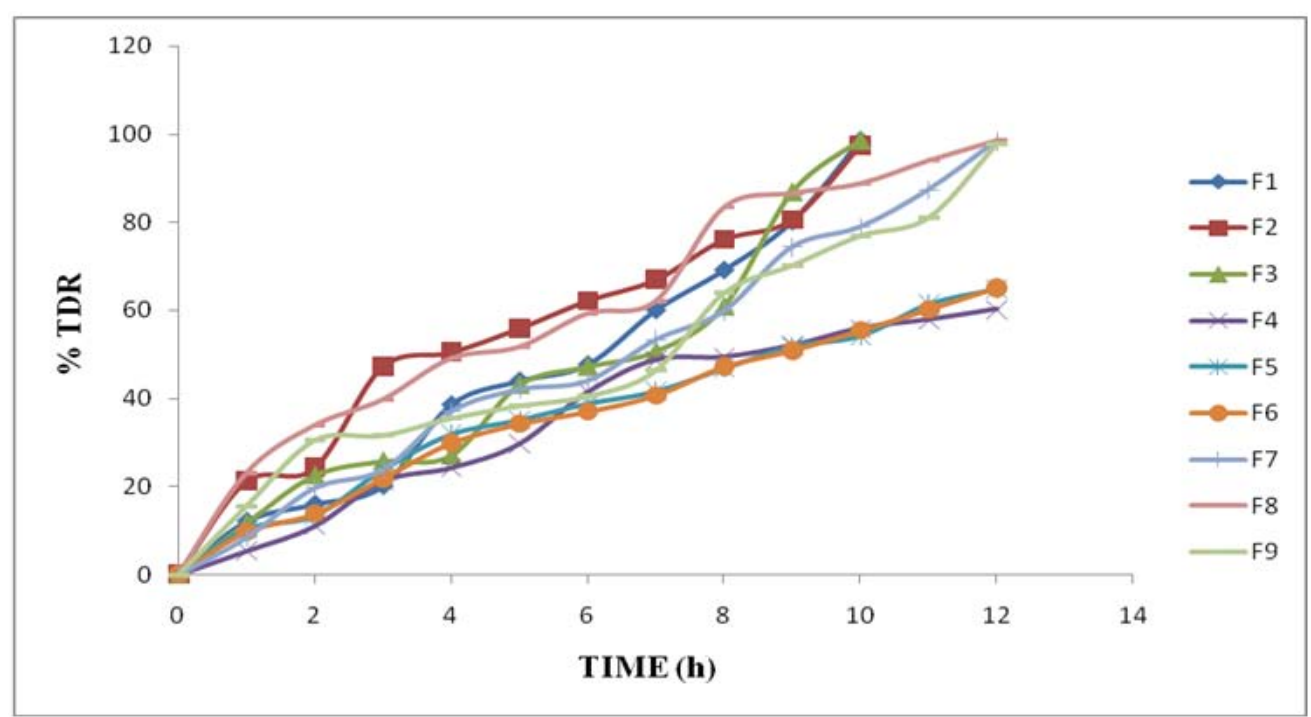

Fig. 3: Percentage drug release of losartan potassium from formulation F1 to F9, all values were calculated mean \pm standard deviation; $\mathrm{n}=3$

Table 5: In vitro drug release kinetic studies of different formulations

\begin{tabular}{|c|c|c|c|c|c|}
\hline \multirow[t]{2}{*}{ Formulation } & Zero-order & First order & Higuchi & Hixon Crowell & \multirow{2}{*}{$\begin{array}{l}\text { Release } \\
\text { exponent (n) }\end{array}$} \\
\hline & \multicolumn{4}{|c|}{ Regression coefficient $\left(\mathrm{R}^{2}\right)$} & \\
\hline F1 & 0.975 & 0.629 & 0.926 & 0.802 & 0.868 \\
\hline $\mathrm{F} 2$ & 0.962 & 0.71 & 0.958 & 0.854 & 0.669 \\
\hline F3 & 0.93 & 0.613 & 0.863 & 0.754 & 0.760 \\
\hline F4 & 0.949 & 0.976 & 0.978 & 0.969 & 0.987 \\
\hline F5 & 0.981 & 0.985 & 0.986 & 0.989 & 0.759 \\
\hline F6 & 0.99 & 0.988 & 0.988 & 0.993 & 0.780 \\
\hline F7 & 0.989 & 0.715 & 0.959 & 0.872 & 0.913 \\
\hline F8 & 0.976 & 0.842 & 0.965 & 0.939 & 0.515 \\
\hline F9 & 0.951 & 0.668 & 0.894 & 0.813 & 0.496 \\
\hline
\end{tabular}

\section{In vitro drug release profile}

In vitro dissolution studies were performed for all the batches of GRDDS of losartan potassium using USP XXIII dissolution test apparatus-II at $50 \mathrm{rpm}, 900 \mathrm{ml}$ of $0.1 \mathrm{~N} \mathrm{HCl}(\mathrm{pH} \mathrm{1.2)}$ used as dissolution media. The in vitro drug release data was given in fig. 3. All the tablet formulations showed more than $8 \%$ drug release within $1 \mathrm{~h}$, except F4, but formulation F8 showed maximum $23.17 \%$ drug release within $1 \mathrm{~h}$. After the ideal study, drug release for formulations F1, and F4 (with HPMC k4m) were found to be $98.64 \%$, after $10 \mathrm{~h}$ and $60.28 \%$ after $12 \mathrm{~h}$, respectively. Formulations F2 and F5 have guar gum the drug releases $97.56 \%$, after $10 \mathrm{~h}$ and $64.83 \%$ after $12 \mathrm{~h}$, respectively, and same like Formulations F3 and F6 having gum karaya the drug releases $98.65 \%$, after $10 \mathrm{~h}$ and $65.24 \%$ after $12 \mathrm{~h}$, respectively. As the drug release could only be observed up to $10 \mathrm{~h}$ in F1-F3 with the sustained release polymer concentration of $23 \%$, a further high concentration of polymer $29.6 \%$ was employed in F4-F6 to sustain the drug release up to $12 \mathrm{~h}$, as the drug release was found to be a function of polymer concentration. As these results were far behind the satisfactory release rate, a combination of polymers in 1:1 ratio the concentration of $23 \%$ was employed to negotiate the slow release characteristics of F7 to F9 formulations, and the drug release was found to be optimum in F9 $(97.77 \%)$ drug release having two natural gums, one is water-soluble (guar gum) and the other is water-insoluble (gum karaya) compared to F7 and F8. Hence, F9 was considered to be the optimized formulation. The drug release data were then fitted to mathematical models such as a zero-order, firstorder, Higuchi, Hixon-Crowell and Korsmeyer-Peppas model and the coefficients of regression values were compared [12]. It was observed that the formulations F1-F3 and F7-F9 followed zero-order release and formulation F4 followed Higuchi release kinetic. The formulations F5 and F6 follow Hixon-Crowell release kinetic. Among all nine formulations, F9 was selected as the best formulation. Data were then subjected to Korsmeyer-Peppas equation for determination of release mechanism and the release exponent ' $n$ ' varied from 0.496-0.987 that indicates F9 having Fickian diffusion and remaining F1 to F8 followed non-Fickian diffusion [13].

\section{CONCLUSION}

This study discourses the formulation and evaluation of gastroretentive tablets of losartan potassium. The effervescent based floating drug delivery was a hopeful approach to achieve in vitro buoyancy. The addition of polymer HPMC $\mathrm{k} 4 \mathrm{~m}$, natural polymers' guar gum, gum karaya and gas generating agent sodium bicarbonate was important to achieve in vitro buoyancy. Formulation F9 showed a preferred drug release profile up to $12 \mathrm{~h}$ following zero-order release kinetics and formulations F1 to F8 followed non-Fickian diffusion except F9 was having Fickian diffusion. Thus, the conclusion of this research work clearly points out, a promising potential of this losartan potassium floating prolong release dosage form is as a substitute to the conventional dosage form for the management of hypertension.

\section{ACKNOWLEDGMENT}

The authors are thankful to spectrum pharma research solutions, Hyderabad Telangana, for providing the necessary research facilities.

Financial support and sponsorship: Nil.

\section{AUTHORS CONTRIBUTIONS}

All the authors have contributed equally

\section{CONFLICTS OF INTERESTS}

Declared none 


\section{REFERENCES}

1. Streubel A, Siepmann J, Bodmeier R. Drug delivery to the upper small intestine window using gastro-retentive technologies. Curr Opinion Pharmacol 2006;6:501-8.

2. Bardonnet PL, Faivre V, Pugh WJ, Piffaretti JC, Falson F. Gastro retentive dosage forms: overview and the special case of helicobacter pylori. J Controlled Release 2006;111:1-18.

3. Timmermans J, Moes AJ. How well do floating dosage forms float? Int J Pharm 1990;62:207-16.

4. Streubel A, Siepmann J, Bodmeier R. Floating matrix tablets based on low-density foam powder: effects of formulation and processing parameters on drug release. Eur J Pharm Sci 2003;18:37-45.

5. Nayak AK, Malakar J, Sen KK. Gastroretentive drug delivery technologies: current approaches and future potential. J Pharm Educ Res 2010;1:1-10.

6. Kothari Abhaykumar H, Manish J. Gastroretentive drug delivery system and its approaches: a review. Int J Pharm Res Development 2013;4:7-18.

7. Rouge N, Buri P, Doelker E. Drug absorption sites in the gastrointestinal tract and dosage form for site-specific delivery. Int J Pharm 1996;136:117-39.

8. Fell JT, Whitehead L, Collet H. Prolonged gastric retention using floating dosage forms. Pharm Technol 2000;24:82-90.

9. Streubel A, Siepmann J, Bodmeier R. Gastroretentive drug delivery system. Expert Opin Drug Delivery 2006;3:217-33.

10. Bramhankar DM, Jaiswal SB. Controlled release medication. Jain MK. editor. Design of controlled drug delivery systems. 1st ed. Delhi: Vallabh Prakashan; 2002. p. 335-7.

11. Minami H, McCallum RW. The physiology and pathophysiology of gastric emptying in humans. Gastroenterology 1984; 86:1592-610.
12. Patel VF, Patel NM, Yeole PG. Studies on the formulation and evaluation of ranitidine floating tablets. Indian J Pharm Sci 2005;67:703-9.

13. Banker GS, Rhodes CT. Target-oriented drug delivery systems and packaging of pharmaceutical dosage forms. Banker GS, Rhodes CT. editors. 3rd ed. New York: Marcel Dekker; 1996. p. 678-721.

14. Samyuktha M, Vasanth PM, Suresh K, Ramesh T, Ramesh M. Formulation and evaluation of gastroretentive floating tablets of losartan potassium. Int J Biopharm 2013;4:18-26.

15. Sandhyarani S, Ramesh A, Krishna KVM. Formulation and evaluation of stable floating tablet of losartan potassium for oral controlled drug delivery system. J Pharm Sci Res 2015;7:946-51.

16. Audumbar DM, Ritesh SB. Development and evaluation of gastroretentive floating tablets of a quinapril HCL by direct compression technique. Int J Pharm Pharm Sci 2017;9:35-46.

17. Ahmed AA, Wedad KA, Al-saady FA. Formulation and evaluation of prochlorperazine maleate sustained floating release tablet. Int J Pharm Pharm Sci 2017;9:89-98.

18. Manojkumar SP, Vidyasagar G, Patil VB. Formulation, optimization and evaluation of floating tablets clarithromycin. Int J Pharm Pharm Sci 2015; 7:320-6.

19. Radhika PR, Nishala N, Kiruthika M, Iswarya S. Design and evaluation of intragastric buoyant tablets of venlafaxine hydrochloride. Asian J Pharm Clin Res 2017;10:166-70.

20. Sreejan M, Jayasri K, Kancherla RA, Lakshmi KK. Alginate-based gastro-retentive raft forming tablets for enhanced bioavailability of tinidazole. Int J Appl Pharm 2017;9:16-21.

21. Bharat WT, Umesh TJ, Shruti GP, Vijay RP. Formulation and in vitro evaluation of floating tablets of cefpodoxime proxetil. Int J Curr Pharm Res 2017;9:18-22.

22. Shah HP, Prajapati ST, Patel CN. Gastroretentive drug delivery systems: from conception to commercial success. J Crit Rev 2017;4:10-21. 